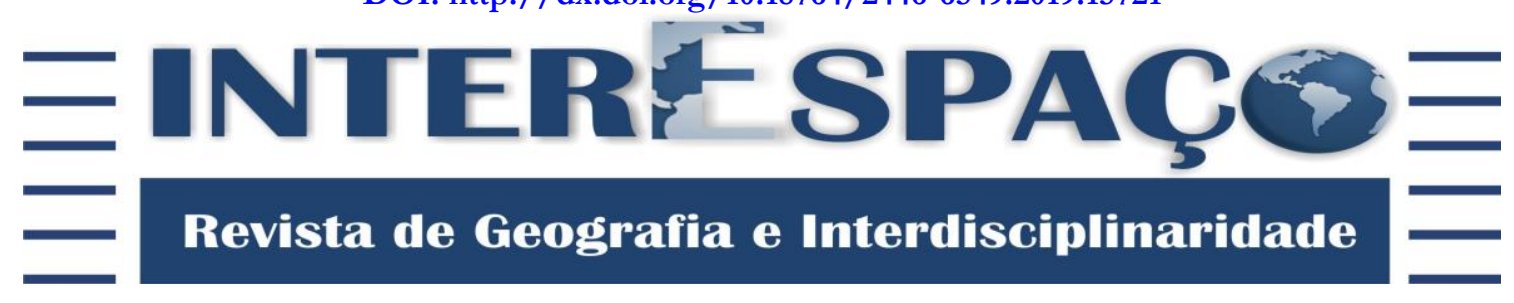

\title{
PRINCESA DO XINGU-PA: educação, sociabilidade e impactos sociais em uma agrovila da Amazônia ${ }^{1}$
}

\author{
PRINCESA DO XINGU-PA: educación, sociabilidad e impactos sociales en una \\ comunidad rural de Amazonia
}

\section{PRINCESA DO XINGU-PA: education, sociability and social impacts in an Amazon agro-village}

\section{César Martins de Souza}

Doutor em História pela Universidade Federal Fluminense - UFF. Professor do Programa de PósGraduação em Linguagens e Saberes na Amazônia e do Campus de Bragança da Universidade Federal do Pará - UFPA. Editor da Nova Revista Amazônica - UFPA. cesar@ufpa.br / http://orcid.org/0000-0003-4530-4844

\section{Nelivaldo Cardoso Santana}

Mestre em Linguística pela Universidade Federal de Pernambuco - UFPE. Professor da Faculdade de Letras da Universidade Federal do Pará - UFPA/Campus de Altamira. nelioscpoeta@gmail.com / http://orcid.org/0000-0002-9039-4589

\section{Edilane Bezerra Amorim}

Mestranda em Geografia pela Universidade Federal do Pará - PPGEO/UFPA. edilaneamorim.ufpa@gmail.com / http://orcid.org/0000-0002-2716-916X

Recebido para avaliação em 01/07/2019; Aceito para publicação em 18/08/2019.

\section{RESUMO}

Devido à invisibilidade social da Amazônia, suas agrovilas e seus caminhos no interior das matas se tornam invisíveis à sociedade brasileira. A partir de entrevistas e observação direta, em pesquisas de campo na agrovila Princesa do Xingu, localizada em Altamira-PA, realizadas antes e depois da construção da Hidrelétrica Belo Monte, o presente artigo busca analisar as transformações nas práticas de sociabilidade e educação escolar a partir deste empreendimento. A educação e o transporte possuem dificuldades e limitações que desafiam os mais velhos e muitas vezes funcionam como um elemento de expulsão dos mais jovens. Após décadas, a agrovila se tornou um lugar onde os moradores se sentem pertencentes, a despeito dos problemas sociais que enfrentam.

Palavras-chave: Desenvolvimento Econômico na Amazônia; Educação Amazônica; Meio Rural; Planejamento Social.

\section{ABSTRACT}

Due to the social invisibility of the Amazon, their local neighborhood rural villages and their paths in the forests become invisible to the Brazilian society. From interviews and direct observation,

\footnotetext{
${ }^{1} \mathrm{O}$ presente texto é resultado do desenvolvimento de atividades docentes em 2004 e 2005 junto a turmas do Curso de Letras-Língua Portuguesa, Agronomia e de Curso de Extensão ministrado para alunos de graduação, quando tivemos a oportunidade de realizar investigação científica na localidade. Posteriormente, em 2015 e 2016, durante a construção da Hidrelétrica Belo Monte, os dados já coletados foram integrados às atividades do projeto "Da Transamazônica a Transoceânica: memórias, culturas e meio ambiente na integração rodoviária entre Brasil e Peru", coordenado pelo primeiro autor, com apoio de bolsas de iniciação científica da Pró-Reitoria de Pesquisa e Pós-Graduação da Universidade Federal do Pará (PROPESP/UFPA).
} 
through field research in the rural village Princesa do Xingu, located in Altamira-PA, carried before and after the construction of the Belo Monte's Hydropower plant, this article seeks to analyze the changes in sociability and school education practices from this enterprise. Education and transport have difficulties and limitations that challenge old age people and often work as an element to repel the youngest ones. After decades, the agricultural village became a place where the live-in people feel they belong to, despite the social problems they face.

Keywords: Economic Development in the Amazon; Amazon Education; Rural Environment; Social Planning.

\section{RESUMEN}

Puesto que hay una invisibilidad social de la Amazonia, sus comunidades rurales y sus caminos en el interior de la selva se vuelven invisibles para la sociedad brasileña. A partir de entrevistas y de la observación directa en investigaciones de campo en la comunidad agrícola Princesa do Xingu, ubicada en Altamira-PA, llevadas a cabo antes y después de la construcción de la Hidroeléctrica Belo Monte, esto artículo busca analizar los cambios en las prácticas de sociabilidad y educación escolar desde el comienzo de la implantación de esto emprendimiento. La educación y el transporte presentan dificultades y limitaciones que desafían a los adultos mayores y funcionan como un elemento de expulsión de los más jóvenes. Después de décadas, la comunidad agrícola se transformó en un lugar donde sus residentes sienten que pertenecen a esa comunidad, a pesar de los problemas sociales que enfrentan.

Palabras clave: Desarrollo Económico en la Amazonia; Educación Amazónica; Medio Rural; Planificación Social.

\section{INTRODUÇÃO}

O presente artigo foi elaborado a partir de pesquisa de campo, com observação do cotidiano da agrovila e entrevistas com moradores, iniciada em 2004, com prosseguimento nos anos de 2005 e 2015. Ainda em 2005 foi organizado o material e elaborado o esboço da primeira parte deste texto. Em 2015, verificamos a importância dos dados que ainda não haviam sido publicados e resolvemos ir novamente a campo a fim de comparar aquele momento da agrovila com o atual, marcado pelas transformações decorrentes do processo de construção da Usina Hidrelétrica Belo Monte (UHBM) e do asfaltamento da estrada que liga Princesa do Xingu à sede do município de Altamira ${ }^{2}$.

Desta forma, o retorno à campo, em 2015, possibilitou analisar os dados deste momento, com a pesquisa realizada em 2004-2005, permitindo comparar o antes e depois da agrovila, frente à construção da Hidrelétrica Belo Monte.

A Agrovila Princesa do Xingu localiza-se a $27 \mathrm{~km}$ da zona urbana do município de Altamira, região sudoeste do estado do Pará, próximo à rodovia Transamazônica (BR-230), especificamente na rodovia Magalhães Barata, popularmente denominada de Estrada da

\footnotetext{
${ }^{2} \mathrm{O}$ município de Altamira fica localizado no sudoeste do estado do Pará, na Amazônia brasileira. A cidade de Altamira, devido sua localização estratégica, veio a servir de base para a construção da Hidrelétrica Belo Monte, no rio Xingu.
} 
| César Martins de Souza | Nelivaldo Cardoso Santana | Edilane Bezerra Amorim |

Bethânia ${ }^{3}$. Essa agrovila funciona como polo de referência à educação para alunos dos travessões ${ }^{4}$ próximos, desde quando foi fundada, em 1972, através do Programa de Colonização Nacional, que tinha seu eixo na Rodovia Transamazônica (cf. SILVA; SOUZA, 2018 e CARDOSO; MULLER, 1978), realizado pelo Instituto Nacional de Colonização e Reforma Agrária (INCRA).

Segundo Rego (2017), o Programa de Colonização Nacional, criado em 1970, durante o governo do general-presidente Emílio Garrastazu Médici, previa a construção de escolas, postos de saúde, centros comunitários, igrejas, casas, praças, campo de futebol e ruas, para receber os grupos de migrantes, compostos por famílias agricultoras.

O presente texto reúne as atividades desenvolvidas em pesquisa de campo, com entrevistas e observação direta realizadas pelos autores, para conhecer a realidade, o cotidiano e as relações sociais na agrovila. Nossa pesquisa, em 2004 e 2005, ocorreu em diversos momentos, juntamente com as turmas de Letras e Agronomia, do Campus de Altamira/UFPA: os estudantes se dividiam para investigar sobre variados temas, como educação, saúde, trabalho, sociabilidade, religiosidade. Estivemos nestes momentos com os alunos e também em outros, sem a presença deles, para observar o cotidiano da agrovila, caminhar pelas ruas, conversar com as pessoas e entrevistá-las. Em 2015, regressamos para realizar nova pesquisa de campo e ter a oportunidade de comparar com o momento anterior, no sentido de verificar e analisar as possíveis mudanças e as percepções dos moradores sobre as transformações decorrentes do asfaltamento da Estrada da Bethânia e da construção da UHBM, no rio Xingu.

\section{EDUCAÇÃO, LAZER E SOCIABILIDADE ANTES DA UHBM}

A agrovila Princesa do Xingu foi inaugurada pelo INCRA, em 1972, e recebeu famílias de migrantes, sobretudo nordestinos, escolhidos em seus municípios de origem para se estabelecerem nos projetos de ocupação da Transamazônica. As agrovilas possuíam originalmente infraestrutura construída nas agrovilas, para possibilitar a instalação dos agricultores em um sistema que Rego (2017) denomina de planejamento arquitetônico baseado em um sistema de integração urbano-rural.

Segundo os moradores, as melhorias implementadas posteriormente na infraestrutura são resultantes de movimentos de mobilização e organização popular junto

\footnotetext{
${ }^{3}$ Assim é conhecida, entre os moradores locais, a rodovia Magalhães Barata. Esta rodovia é o acesso terrestre entre a Agrovila e a área urbana de Altamira.

${ }^{4}$ Os travessões são estradas perpendiculares à rodovia principal, nos quais se encontram lotes de agricultores e também vilas que surgiram após a construção da Transamazônica.
} 
aos órgãos públicos, como a construção de outra escola de Ensino Fundamental, em 1983, bem como a oferta de ensino médio, que ocorreu por meio de elaboração de documentos reivindicatórios, reuniões e debates coletivos. Esses são momentos em que os moradores negociam turnos de fala, elaboram atas, lista de frequência, o que leva à construção de um processo político pedagógico, reforçando os laços de coesão e de pertencimento dos moradores à comunidade. As conquistas como fruto da ação coletiva dos moradores da Princesa do Xingu reiteram estudos que analisam o campo, como o lócus onde a educação é uma prática que transcende a escola formal, pois advém das organizações dos agricultores em seu cotidiano na família e na comunidade.

Logo após a construção da Transamazônica, ainda durante o governo de Médici, os migrantes recebiam um lote de cem hectares, do governo federal, para que pudessem desenvolver a agricultura, mas, como os lotes geralmente se localizavam distantes da agrovila, muitos colonos construíram casas junto às plantações ou buscaram a obtenção de terras ou trabalhos próximo à Princesa do Xingu, para que pudessem ficar junto às suas famílias e ao mesmo tempo oportunizar acesso à escola aos filhos.

Apesar de a agrovila se localizar próxima à Altamira, antes do asfaltamento da Estrada da Bethânia o acesso era prejudicado pelas más condições de trafegabilidade, o que provocava um maior distanciamento da agrovila para a zona urbana do município. Os moradores mais velhos manifestavam gostar do distanciamento da cidade, pois acreditavam que assim podiam ter mais tranquilidade, dormir com as portas abertas, conversar à soleira com os vizinhos e desenvolver suas atividades de trabalho e de sociabilidade, sem temer a violência.

Os mais jovens, entretanto, demonstravam incômodo com a situação, expressando o desejo de não somente frequentar a cidade, como também de vir a migrar definitivamente para a zona urbana de Altamira ou para cidades maiores, como a capital do estado do Pará, Belém, objetivando acesso aos serviços e práticas de lazer e sociabilidade. Rose, 19 anos, moradora da agrovila, falou sobre diversos temas, como família, educação, lazer e trabalho e manifestou seus sonhos e perspectivas futuras:

\footnotetext{
Moro aqui há muito tempo e estudo aqui, mas o ruim é que os professores faltam e às vezes fica sem professor. Às vezes acho chato morar aqui, mas o que eu vou fazer. Eu gosto é de ir para Altamira [sede do município], lá é que é divertido e tem gente. Sonho em um dia ser médica, já até pensei em ir trabalhar na casa de uma senhora lá em Belém, porque aí eu entro na faculdade e me torno médica (ROSE, 2004) 5 .
}

${ }_{5}^{5}$ Todos os nomes dos entrevistados são fictícios para preservar suas identidades. 


\section{| César Martins de Souza | Nelivaldo Cardoso Santana | Edilane Bezerra Amorim |}

As ideologias do desenvolvimento e da afirmação do capitalismo brasileiro veem o campo como espaço negativo, do atraso. Essa ideologia marca todo o processo educacional em sentido amplo, o que leva, sobretudo os mais jovens, a acreditarem que a saída do campo é uma forma de conseguir ascensão social. O campo seria, assim, o lugar monótono, sem divertimentos, enquanto a cidade traz a possibilidade de acesso aos bens e serviços desejados e/ou necessários.

Em seu estudo sobre educação do campo, Souza (2008) analisa as ideologias construídas a partir da implantação do capitalismo autoritário brasileiro, nas primeiras décadas do século XX, que buscaram afirmar o campo como símbolo do atraso. Desta forma, em outro texto, Souza (2017) também problematiza a construção de estudos sobre educação do campo, bem como sua implementação no Brasil que busca se opor em uma precarização do ensino público, que estimula a baixa autoestima, sobretudo dos filhos de agricultores.

Rose, uma jovem mãe solteira, expressava ideias que consideram o campo como lugar negativo. Ela afirmava a superioridade da cidade, e um desejo de obter trabalhos de baixa remuneração em Belém, uma cidade com mais de um milhão de habitantes, como uma forma de vir a se tornar médica para conseguir salários, eventualmente mais elevados, e sair de vez do campo. Para Souza \& Oliveira (2003), além das ideologias, há o problema das más condições de serviços públicos básicos, oferecidos pelo Estado brasileiro, que funcionam como um mecanismo de expulsão dos moradores do campo para as cidades:

\footnotetext{
A precariedade das condições de vida de amplos segmentos do meio rural, que sobrevivem sob formas duras de trabalho diário, com restrito acesso a aparatos tecnológicos e infra-estruturais que garantam o mínimo de conforto; as situações socioeconômicas, consequência das precárias formas de trabalho, que não asseguram um padrão econômico de investimento e estabilidade; a ausência de políticas sociais capazes de garantir o atendimento das necessidades básicas, como a saúde, a previdência, o transporte, a habitação, a educação, enfim, um conjunto expressivo de direitos... (SOUZA; OLIVEIRA, 2003, p. 215).
}

A precarização do trabalho e as dificuldades de acesso a alguns serviços contribuem para a construção do "desejo" dos jovens de migrarem para as cidades em busca de alternativas econômicas e sociais diferentes daquelas do campo. A carência de aparatos tecnológicos, como afirmam Souza \& Oliveira (2003), também contribui para a expulsão dos jovens que buscam determinados serviços na zona urbana. Em Princesa do Xingu, até 2015, os telefones celulares funcionavam somente em alguns lugares da agrovila, não havendo também rede de acesso à internet disponível e a televisão está disponível apenas através de antenas parabólicas. 
Apesar das dificuldades e do etnocentrismo presentes na sociedade brasileira em relação à vida no campo, o cotidiano era marcado também por muitos momentos de lazer e sociabilidade. No fim da tarde, muitos gostavam de se reunir nas casas para conversar e assistir televisão juntos. Aos sábados e domingos, sob a liderança de um dos moradores mais antigos, conhecido como Fussura, ocorriam, com frequência, partidas e torneios de futebol, atraindo times e torcidas de outras comunidades da Transamazônica.

Com a vinda dos muitos jogadores de outras localidades, a movimentação ao redor do campo, localizado em um ponto central da comunidade era grande. Os dois bares localizados próximo ao campo ficavam lotados por pessoas circulando para jogar, assistir ou apenas aproveitar a oportunidade para se reunir com vizinhos e conversar. Assim, o espaço do campo de futebol não era frequentado somente pelos praticantes e simpatizantes de esporte, muitos iam até lá para conversar sobre a família, o trabalho, os times de coração.

Relações de sociabilidade, conversas em reuniões familiares e noticiários traziam cotidianamente informações sobre o futebol, fazendo com que, até mesmo não praticantes e não simpatizantes, possuíssem conhecimento sobre o jogo, clubes e atletas. "O futebol se apresenta hoje em uma verdadeira língua franca, atravessando todas as fronteiras" (ALVITO, 2006, p. 456). Ao mesmo tempo em que é "marcado pela paixão e pelo arrebatamento coletivo, o futebol torna-se o carro chefe da indústria do entretenimento" (ibidem), sendo consumido em bares, restaurantes, lojas esportivas e pelas empresas de propaganda do mundo.

É comum ver moradores, sobretudo crianças e jovens do sexo masculino, caminhando pelas ruas com camisas de clubes brasileiros ou de clubes europeus. Alvito denomina esse fenômeno de globalização do futebol, tornando populares clubes de outras regiões do Brasil, ou até mesmo de outros países, devido à divulgação e a transmissão por emissoras de televisão. Os debates sobre o esporte são não apenas sobre o Campeonato Brasileiro de Futebol, como também sobre as ligas europeias de maior destaque, como inglesa, italiana, espanhola e alemã. Como é possível assistir televisão apenas através de antenas parabólicas, as pessoas se limitam à programação de outros estados e outros países, fazendo com que, por exemplo, o Campeonato de Futebol do Estado do Pará seja praticamente desconhecido.

As partidas e torneios disputados aos finais de semana são um importante momento de sociabilidade, frequentado por avós, pais, filhos, casais de namorados. Apesar de fazer um estudo etnográfico mais voltado para a zona urbana da capital do Rio de Janeiro, Guedes (1998), ao estudar os significados do futebol brasileiro, traz reflexões 
importantes para pensar a sociabilidade esportiva na Princesa do Xingu. A autora considera que os jogos de futebol praticados informalmente, conhecidos popularmente no Brasil como peladas, mesmo sendo praticados como atividades de lazer, exigem determinado nível de organização, apesar de compor o tempo de descanso dos trabalhadores. O "[...] tempo do peladeiro é o tempo do não trabalho. Por isso estes jogos compõem a paisagem comum dos fins-de-semana, em particular aos domingos, nos bairros de trabalhadores" (GUEDES, 1998, p. 87).

Principalmente às noites e aos fins de semana, os dois bares, bem como os bancos em torno das árvores localizadas à frente das residências, servem de ponto de encontro, de lugar para conversar e contar histórias. As escolas, também, se constituem, além de um lugar onde se oferece educação formal, em espaços de reunião e encontro de moradores.

Há duas escolas na agrovila, Escola Municipal de Ensino Fundamental (EMEF) Professor Raimundo Alves da Costa, construída em 1983, oferta o Ensino Fundamental, e a EMEF Princesa do Xingu, construída em 1972, sempre ofertou o Ensino Fundamental e há alguns anos passou a atender a demanda do Ensino Médio, em sistema regular/modular. No sistema regular, as disciplinas são ministradas por professores do quadro da escola com uma determinada carga horária semanal ao longo de todo o ano. Diferentemente, no sistema modular, os professores partem da capital, Belém, ou de Altamira para ministrarem disciplinas em regime intensivo, de modo que um mesmo professor permanece ministrando disciplina em determinado período.

Caldart (2004) ao discutir e propor os "Elementos para construção do projeto político pedagógico da Educação do Campo" afirma que, no Brasil, de modo geral, é imposto às comunidades rurais um sistema de ensino que reproduz os modelos urbanos, aprofundando a baixa autoestima e exclusão social das populações do campo. Caldart considera também que, em sentido oposto, a educação do campo se constitui num movimento dinâmico organizado pelos próprios agricultores, para atender as suas demandas:

\footnotetext{
[...] um projeto de educação dos trabalhadores e das trabalhadoras do campo, gestado desde o ponto de vista dos camponeses e da trajetória de luta de suas organizações. Isto quer dizer que se trata de pensar a educação (política e pedagogia) desde os interesses sociais, políticos, culturais de um determinado grupo social; ou trata-se de pensar a educação (que é um processo universal) desde uma particularidade, ou seja, desde sujeitos concretos que se movimentam dentro de determinadas condições sociais de existência em um dado tempo histórico (CALDART, 2004, p. 12).
}

A demanda de alunos para o Ensino Fundamental é extensa, por isso as aulas são no período diurno e noturno através do sistema de Educação para Jovens e Adultos (EJA), 


\title{
|César Martins de Souza | Nelivaldo Cardoso Santana | Edilane Bezerra Amorim |
}

enquanto o Ensino Médio ocorre unicamente em período noturno. Muitos professores se deslocam da zona urbana de Altamira para ministrar as aulas. Os conteúdos são os mesmos da escola da cidade, o que pode levar a um distanciamento da comunidade escolar para a realidade vivenciada pelos alunos na agrovila. Do mesmo modo que em outros lugares do Brasil, na Princesa do Xingu o modelo de educação fundamenta-se numa proposta de ensino que na prática nega os saberes locais. Ao discutir sobre educação do campo, currículo e diversidades culturais, Pereira \& Pereira (2016) consideram que:

\begin{abstract}
O modelo de educação pensado para a cidade é reproduzido no campo, mostrando que o campo está sempre subordinado a aceitar a educação que está presente na zona urbana, negando ao homem do campo a possibilidade de se tornar protagonistas da construção coletiva da educação, não considerando que este seja capaz de pensar por si próprio (PEREIRA; PEREIRA, 2016, p. 123).
\end{abstract}

Os autores afirmam que ainda existem em muitos lugares do Brasil as chamadas escolas rurais, que não atendem às demandas dos agricultores e ainda ignoram os saberes e as especificidades dos sujeitos do campo, pois se baseiam em visões que enxergam os agricultores como meros fornecedores de mercadorias para as cidades. Por outro lado, a educação do campo defende práticas diferentes, pois é uma proposta que vêm do próprio campo:

\footnotetext{
a Educação do Campo se diferencia da educação rural, pois é construída por e para os diferentes sujeitos, territórios, práticas sociais e identidades culturais que compõem a diversidade do campo. Ela se apresenta como uma garantia de ampliação das possibilidades de homens e mulheres camponeses criarem e recriarem as condições de existência no campo. Portanto, a educação é uma estratégia importante para a transformação da realidade dos homens e das mulheres do campo, em todas as suas dimensões (MASCARENHAS et al., 2012, p. 16-17).
}

Mascarenhas et al. (2012) consideram que as dificuldades e dissonâncias da educação rural em relação às vidas dos trabalhadores faz com que os filhos deles sejam expulsos para estudar e buscar outras perspectivas. Esta prática leva muitas vezes a migração de toda a família definitivamente, não por uma opção consciente, mas por não conseguirem vivenciar seus próprios modos de vida, frente a um sistema políticoeconômico que não enxerga o campo como um lugar com suas próprias especificidades.

Para Caldart (2004), há diferenças marcantes da proposta dos movimentos sociais do campo, em relação às práticas excludentes e englobantes da educação rural, adotada majoritariamente em todo o país: 
A Educação do Campo faz o diálogo com a teoria pedagógica desde a realidade particular dos camponeses, mas preocupada com a educação do conjunto da população trabalhadora do campo e, mais amplamente, com a formação humana. E, sobretudo, trata de construir uma educação do povo do campo e não apenas com ele, nem muito menos para ele (CALDART, 2004, p. 18).

$\mathrm{Na}$ concepção do professor João, esse era o grande desafio para os gestores da educação básica, "o planejamento do ensino escolar deveria ser especificado, deveria ser feito com relação ao dia-a-dia dos agricultores". O professor alega ainda que, “durante o plantio o pai precisa do filho. Por isso no início das aulas alguns alunos geralmente perdem aula [...], quando é nas provas principais do meio do ano, o pai precisa do filho para a colheita" (JOÃO, 2004).

Tim Ingold (2015) considera que a educação escolar ocidental, de modo geral, padece de problemas conceituais que levam a distorções nas práticas oriundas das concepções presentes nas sociedades. A educação escolar segue padrões e busca colocar nas mentes dos alunos o conhecimento que se acredita necessário, sem que haja métodos voltados para a aprendizagem baseada nas experiências e conhecimentos adquiridos ao longo da vida: "educar é levar os noviços para o mundo lá fora, ao invés de - como é convencional hoje - inculcar o conhecimento dentro das suas mentes. Significa, literalmente, convidar o aprendiz para dar uma volta lá fora” (INGOLD, 2015, p. 23).

Os depoimentos dão conta de que é necessário a escola do campo seguir o calendário agrícola, respeitando os ciclos produtivos para os agricultores. Contudo, do modo como as políticas de ensino são implementadas, os filhos de agricultores são induzidos pelo sistema político a migrarem para a cidade, em busca de acesso às tecnologias e opções de lazer, ou mesmo em busca de empregos não relacionados às atividades agrícolas ou pecuárias.

A maioria dos docentes que atuam na agrovila, sobretudo os advindos da parte urbana do município, não possuem formação continuada ou específica para trabalharem na/com a educação do campo e muitos deles não buscam conhecer melhor o cotidiano da localidade. O professor que vem da cidade para atuar no sistema regular/modular muitas vezes não se reconhece como um sujeito partícipe da vida da escola do campo, esse professor se vê numa escola no campo, o que afeta diretamente o comportamento social e a prática do professor em sala de aula.

Devido contar com alguns professores da cidade e outros da própria agrovila, o sistema acabava por reunir em uma mesma escola, o regular, ministrado por professores que residem na agrovila, com o modular, por professores advindos da zona urbana de Altamira. Alguns professores, como Mirla (2004), moradora da agrovila, se expressavam 
inconformados com essa modalidade de oferta, modular-regular numa mesma escola, pois poderiam dificultar o trabalho com os conteúdos e o processo de aprendizagem.

Durante o período chuvoso, conhecido na Amazônia brasileira como "inverno amazônico" - de dezembro a junho - quando as chuvas são mais intensas, havia ainda outro elemento complicador: o professor oriundo da cidade tinha dificuldades para chegar à comunidade, devido às estradas ficarem praticamente intrafegáveis e, por esta razão, os alunos podiam ficar sem aula por um ou mais dias. Devido a esses e outros problemas, alguns filhos de agricultores se mudavam para a cidade para dar continuidade aos seus estudos. Faziam isso pensando em um dia retornar "formados" para a localidade de origem, para ajudar os pais nas atividades do campo ou mesmo lecionar.

\section{EDUCAÇÃO, LAZER E SOCIABILIDADE NO CONTEXTO DE BELO MONTE}

A agenda que prevê a instalação dos chamados grandes projetos de integração e desenvolvimento na Amazônia estende-se da década de 1970 aos dias atuais. Como prova da prorrogação dessa agenda, tem-se a partir de 2011 o início da construção da UHBM, considerada a terceira maior usina hidrelétrica do mundo. Dada a magnitude do projeto e as alterações que provoca na dinâmica de vida das pessoas nas comunidades locais, pergunta-se: quais pressões sociais o projeto da UHBM causa sobre as comunidades locais em Altamira e como localidades a exemplo da agrovila Princesa do Xingu são atingidas pela construção deste empreendimento?

Em 2015, a EMEF Princesa do Xingu contava com aproximadamente 217 alunos nas turmas do Ensino Fundamental no turno da manhã, no período da tarde funcionam as turmas do Ensino Médio. A escola na comunidade funciona para atender aos alunos da comunidade e das propriedades rurais adjacentes sendo que, até o ano de 2009, o Ensino Médio funcionou na modalidade denominada Sistema Modular de Ensino (SOME) ${ }^{6}$. Nessa modalidade, o professor ministra uma disciplina, em seguida vem outro professor com outra disciplina, chamada também de "disciplinas blocadas".

As práticas educativas escolares baseadas em módulos, geralmente negligenciam os saberes locais, passando ao cumprimento de agenda escolar que pouco prepara crianças e

\footnotetext{
${ }^{6}$ O Sistema de Organização Modular de Ensino (SOME) funciona por meio de uma parceria entre Estado, município e comunidade: o Estado disponibiliza o professor; o município oferta as salas de aula e a comunidade oferta alojamento ao professor. No SOME o professor desloca-se para a comunidade para ministrar uma disciplina em até 50 dias.
} 
jovens, ao fim do período escolar, para sua emancipação e crescimento pessoal. Para Corrêa:

Essa lógica de organização de ensino e de educação está fundada no paradigma da ciência moderna, expresso no método matemático cartesiano e na racionalidade positivista, o qual está, indissociavelmente, vinculado a um paradigma de relação social de produção capitalista urbano-industrial (CORRÊA, 2005, p. 169).

Em razão do empreendimento Belo Monte muitas famílias se mudaram da Princesa do Xingu para a sede do município de Altamira a fim de trabalharem nas empresas do Consórcio Construtor de Belo Monte $(\mathrm{CCBM})^{7}$, levando os alunos a serem transferidos para escolas da cidade para acompanhar seu pais. Mas, quando estes eram demitidos do emprego, logo retornavam às escolas da Princesa do Xingu. Antes do empreendimento, as famílias se deslocavam entre uma comunidade e outra para se acomodarem às ofertas de empregos no campo, porém, desde 2011, esse deslocamento passou a ocorrer de modo acelerado entre a Princesa do Xingu e a cidade de Altamira.

Para o professor Festemino, morador da agrovila, essa ida e vinda do educando, sobretudo do campo para a cidade, impacta o rendimento escolar do aluno, que "ora vê um conteúdo depois está vendo outro”. A construção da UHBM gerou, em certa medida, uma pressão sobre as matrículas no sistema educacional na região diretamente atingida pelo empreendimento, trazendo educandos de diferentes regiões do país, que acabaram sobrecarregando escolas locais, e forçando um deslocamento de educandos do campo para a cidade. No caso da Princesa do Xingu, para o professor Festemino (2015), “a criança será muito prejudicada por ficar ora em uma escola, ora noutra”.

A pressão sobre os estabelecimentos de ensino, durante a construção de Belo Monte, geraram diferentes consequências. Para o Instituto Socioambiental - ISA (2015), as obras provocaram uma sobrecarga de pessoas em todos os setores, sobretudo de AltamiraPA e as escolas não conseguiram responder satisfatoriamente às pressões provocadas pelas altas demandas de novos alunos. O ISA (2015) analisa ainda que, durante a construção da UHBM, houve piora nos indicadores de abandono e reprovação escolar, informação que coaduna com as palavras da professora Mirla, novamente entrevistada em 2015:

Os alunos deixam de vir à escola porque os pais saíram cedo demais para trabalhar nas empresas da obra [Belo Monte]. Temos notado também que nossos alunos estão chegando atrasados nas aulas ou, simplesmente, faltando [...] Isso prejudica o aluno e o trabalho do professor (MIRLA, 2015).

${ }^{7}$ CCBM é o consórcio de empresas formado com o fim de construir a Hidrelétrica Belo Monte. 
Em geral, os modelos de produção capitalista, sobretudo dos grandes projetos na Amazônia brasileira, afetam o cotidiano das crianças e jovens, como os da Princesa do Xingu, que desde o início da construção da UHBM tornaram-se sujeitos mais vulneráveis diante das condições de trabalho que os pais assumem na busca de um "emprego melhor". As relações entre função ocupacional dos pais e a política de funcionamento da escola, com seus horários de entrada e saída, entram em conflito com as novas demandas sociais das famílias. A UHBM cria, a partir da oferta de novos empregos aos agricultores, pressão e novas demandas às tarefas dos professores da agrovila.

A construção da hidrelétrica atraiu para fora da agrovila os agricultores, de modo que Belo Monte reproduz práticas dos chamados projetos de desenvolvimento que se impõem como um mecanismo de transformação social profunda nas vidas das populações locais (MIRANDA NETO; HERRERA, 2016). Esse modelo, aliado a visões e políticas que desconsideram a especificidade da educação do campo, desde antes da UHBM, tem como consequência a manutenção de uma escola com características urbanas, porém voltada para sujeitos do campo. Vendramini (2015, p. 65) demonstra preocupação com este quadro, ao afirmar que: "O futuro das escolas está diretamente relacionado com o futuro do campo, um espaço, como já anunciado aqui, em crescente urbanização e mudanças, que implicam a saída de grande parte da população rural".

Molina e Fernandez (2004) compreendem que os processos de desenvolvimento no campo deveriam se aliar aos interesses das comunidades locais, para sistematizar pesquisa e novos projetos para as comunidades locais. Construir os projetos de desenvolvimento no campo perpassa pela construção de uma escola do campo que se preocupa com a comunidade, articulando trabalho e educação. Na Princesa do Xingu, embora os professores e outros atores sociais percebam os efeitos causados pela oferta de empregos na construção da hidrelétrica, sentem-se fragilizados e até mesmo impotentes para enfrentar as dificuldades.

Aquelas ofertas de emprego afetam também a dinâmica de trabalho dentro da própria comunidade Princesa do Xingu, com a mão de obra local sendo destinada para outro lugar, as antigas fronteiras de trabalho ficam sem a mão de obra que antes dispunham. O agricultor que, antes fazia os trabalhos do campo, deixou essas tarefas para atuar como pedreiro, porteiro, auxiliar de serviço geral, etc. A professora Mirla declarou que, "hoje em dia, a gente não consegue mais ninguém nem para limpar uma roça; estão todos na Belo Monte" (MIRLA, 2015). As novas ofertas de serviços ao homem do campo provocam o êxodo rural ou o deslocamento diuturno dos trabalhadores, voltando à tarde ou à noite para suas casas no campo. 
|César Martins de Souza | Nelivaldo Cardoso Santana | Edilane Bezerra Amorim |

Desse modo, a antiga linha que distanciava o campo da cidade praticamente desaparece na Princesa do Xingu, pois, assim como os agricultores vão para a cidade trabalhar durante o dia, alguns professores se deslocam para a escola da comunidade para trabalhar, em um movimento inverso à pendularidade campo-cidade. A escola dispõe, por exemplo, de duas professoras (que vêm da sede do município) para acompanhar alunos que apresentam dificuldades de aprendizagem. Trata-se do chamado reforço escolar.

A escola do campo apresenta atipicidades complexas que refletem os aspectos do contexto em que se encontra. A EMEF da Princesa do Xingu, segundo o professor Festemino, tem o chamado "aluno fazenda", uma denominação local para alunos cujos pais são "peões" ${ }^{8}$ de fazendas da região. Geralmente, esses pais são funcionários de proprietários de mais de uma unidade de fazenda. Por esta razão, os peões mudam com frequência seu local de moradia, para atender as demandas das fazendas do patrão. Devido a isso (ou pelo desemprego), com frequência as famílias se mudam para outra comunidade, forçando, em consequência, a transferência das crianças para outra escola. Com isso, muitos alunos não conseguem criar laços afetivos e de interação social com os professores, com os colegas, com os demais funcionários da escola, o que gera impactos no processo de sociabilidade, refletindo diretamente na aprendizagem.

Alguns dos "alunos fazenda", quando mudam para próximo à Princesa do Xingu, continuam frequentando a mesma escola, porque o transporte escolar (em micro-ônibus e em caminhões "pau-de-arara") busca os alunos. Segundo Festemino, alguns alunos estão a aproximadamente 80 quilômetros de distância da escola, nos chamados travessões ou vicinais. Para esses alunos, as maiores dificuldades ocorrem durante o "inverno amazônico", tornando a trafegabilidade nos travessões praticamente impossível. Devido os micro-ônibus não conseguirem trafegar, muitas vezes usa-se na região os caminhões paude-arara:

Quando chove muito os alunos não conseguem vir para a escola, às vezes o caminhão nem vai buscar esses alunos. Porque a gente já sabe que ele não consegue entrar nos travessões. Como o professor já sabe disso, ele prepara exercícios para os alunos fazerem em casa (FESTEMINO, 2015).

Atuar na escola do campo significa adequar as ações da escola às condições climáticas e aos interesses e necessidades da comunidade. A escola vai se moldando à

\footnotetext{
${ }^{8}$ Indivíduo que cuida do rebanho de gado.

${ }^{9}$ Caminhões pau-de-arara são veículos em que são colocados bancos de madeira na carroceria coberta, como uma forma de adaptá-los para receber passageiros. Estes veículos passaram a ser utilizados em menor número após o início da construção da UHBM, mas por muito tempo prevaleceram como o principal meio de transporte adotado no campo.
} 
| César Martins de Souza | Nelivaldo Cardoso Santana | Edilane Bezerra Amorim |

realidade das crianças e jovens da agrovila. Na Princesa do Xingu, quando o aluno não vem à aula por causa das chuvas, os professores enviam, no dia seguinte, as tarefas escolares para que sejam feitas em casa. A preocupação dos professores está em não atrasar o calendário escolar, por isso eles desenvolvem um mecanismo chamado pelos gestores de planejamento escolar de "intervenção pedagógica".

Por outro lado, como parte das condicionantes exigidas para a construção da UHBM, está o asfaltamento da Estrada da Bethânia que liga a Princesa do Xingu à cidade de Altamira. Para a professora Mirla (2015), ao mesmo tempo em que o asfalto melhora a trafegabilidade, encurtando o tempo de viagem, facilita também a chegada de "pessoas estranhas" à comunidade. O termo "estranho" reforça e delimita a identidade dos moradores do lugar, o sentimento de pertencimento. A chegada de "pessoas estranhas" fez com que a comunidade solicitasse a instalação de um posto policial e ronda policial nos finais de semana pelas ruas da agrovila. Mirla considera que, "antes era tranquilo, a gente via tanta gente por aqui nos finais de semana. Agora é gente indo para os igarapés, vindo para cá, beber cachaça” (MIRLA, 2015).

Nota-se nas palavras da professora certo desconforto com a presença de novas pessoas na comunidade. O asfaltamento da Estrada da Bethânia permitiu que moradores da cidade de Altamira se deslocassem com frequência para a agrovila Princesa do Xingu, para visitar sobretudo os igarapés e bares. Segundo a professora, em alguns casos ocorrem conflitos violentos entre os frequentadores e moradores da comunidade. Se antes das obras de construção da UHBM, os conflitos entre moradores e "estranhos" se resumiam as raras brigas, em torno de disputas nos torneios de futebol e eram narrados de forma jocosa, por nunca haverem se transformado em algo mais grave, agora despertam preocupação não somente da professora Mirla, como também de outros moradores da Princesa do Xingu, sobretudo porque expõem principalmente os mais jovens a cenários marcados pela possibilidade de violência.

Com a ocorrência de casos de violência, a escola, segundo a professora Mirla, precisa se mobilizar para fazer discussão e reflexão acerca do problema, ficando também a cargo do professor, que está em sala de aula, chamar atenção e fazer comentários sobre os riscos de as pessoas se envolverem em brigas.

$\mathrm{Na}$ visão dos moradores entrevistados e com os quais conversamos em caminhadas na Princesa do Xingu, soma-se a isso a morte de Fussura, o principal organizador dos torneios de futebol da agrovila, fazendo com que a prática esportiva nos finais de semana que reunia dos jovens aos mais velhos da agrovila perca progressivamente a força. Mas 
ainda é comum as pessoas irem ao campo da comunidade para brincar futebol na modalidade "grade" 10 , isso porque o número de desportistas reduziu-se drasticamente.

As pessoas estão deslocadas para a cidade ou estão trabalhando diretamente ou indiretamente nas obras de construção da UHBM, com isso, não ocorrem mais com frequência os torneios de futebol, que eram vistos como um momento de confraternização, de celebração entre as pessoas de diferentes comunidades da região. A comunidade acredita que sem o esporte haverá aumento da criminalidade, devido à diminuição da oferta de práticas de lazer e sociabilidade aos mais jovens, pois já observam o aumento do alcoolismo entre os moradores da Princesa do Xingu, incluindo alguns jovens.

\section{CONSIDERAÇÕES FINAIS}

A Princesa do Xingu, nascida em 1972, da megalomania desenvolvimentista que via a floresta amazônica como área a ser ocupada e assim dar lugar à produção agropecuária, ignorando os grandiosos impactos socioambientais que os grandes projetos poderiam provocar, assistiu profundas mudanças em seus quarenta e três anos de existência.

Nos anos 1980 e 1990, após os governos dos generais-presidentes, os moradores enfrentaram o ostracismo, como uma parte do mesmo fenômeno que recaiu sobre a Transamazônica, uma das maiores obras do governo de Emílio Médici e que, por isso, foi esquecida na memória nacional (SILVA; SOUZA, 2018). No início deste século, reivindicavam melhorias na infraestrutura, através de escolas, médicos, pavimentação e aos poucos foram conquistando o que solicitavam. Contudo, os desafios enfrentados por agricultores familiares são grandes em nosso país.

O modelo de ensino marcado por características urbanas aplicado no campo, conhecido como educação rural, prevalece na agrovila, pois, ainda que tenham conseguido mais professores na atual década e a consolidação do ensino médio, as escolas carecem de autonomia que garanta o atendimento às demandas do campo, sobretudo às dos moradores mais jovens. Mas nem só de dificuldades vivem os moradores da agrovila, pois o cotidiano é marcado também por espaços de encontro, pelo lazer em atividades esportivas, como o futebol nos fins de semana, bem como as programações nas igrejas e escolas.

As nossas reflexões demonstraram que o empreendimento hidrelétrico acelerou bruscamente os processos de matrícula e rematrícula dos alunos, isso em razão da

\footnotetext{
10 "Grade" é um termo utilizado no Pará, de um modo geral, para denominar uma modalidade de futebol praticada informalmente, na qual os times são definidos no momento dos jogos. As partidas geralmente duram o tempo de dez minutos ou são encerradas quando uma das equipes marca dois gols. O time vencedor permanece jogando, enquanto o perdedor sai de campo para aguardar novamente sua vez de jogar, pois entra uma outra "grade", ou seja, uma outra equipe.
} 
| César Martins de Souza | Nelivaldo Cardoso Santana | Edilane Bezerra Amorim |

movimentação emprego e desemprego de agricultores que foram trabalhar na construção da UHBM. Outra questão é a existência dos chamados "alunos fazenda", que enfrentam mais dificuldades para consolidar vínculos com os colegas, com os professores e com a escola, devido à sazonalidade de sua presença em diferentes escolas, em função dos constantes deslocamentos de seus pais, em busca de trabalho.

Foi inaugurado, em 2015, o asfalto da estrada que interliga a agrovila à sede do município, o que facilitou e ampliou o deslocamento dos moradores para a cidade, para acessar serviços bancários, de saúde, previdência, comércio, encontrar seus amigos e parentes e estudar nos cursos superiores ofertados em diferentes instituições públicas e privadas.

Ao mesmo tempo em que o asfalto traz benefícios à população, o acesso facilitado à agrovila também trouxe problemas, permitindo não apenas maior trânsito dos moradores para a zona urbana, como também de pessoas advindas de outros lugares para a agrovila. Há relatos de surgimento de situações de violência como arrombamentos e conflitos decorrentes de discussões dos moradores com visitantes, e também o aumento dos casos de alcoolismo.

Muitos moradores venderam suas casas e partiram para a cidade em busca dos postos de trabalho proporcionados pela construção da Hidrelétrica Belo Monte. Após o auge das obras, ficaram desempregados, motivo que os levou a buscar regressar para a agrovila, contudo, muitos não conseguiram comprar novas casas e retornar. Apesar dos novos e velhos problemas na Agrovila Princesa do Xingu, as pessoas se identificam com o local, de forma que é comum ver os moradores, sobretudo os mais antigos, expressarem não se imaginar vivendo em outro lugar.

Assim, a Princesa do Xingu é um lugar que vivencia, a despeito dos problemas sociais que enfrenta, um cotidiano marcado por momentos de sociabilidades, de encontros para diálogos e comemorações coletivas que reforçam os laços de parentesco e amizade. Apesar de ainda continuarem existindo, os encontros para atividades de lazer, comemorações entre amigos, parentes e vizinhos, torneios de futebol, reuniões nas igrejas, nos bancos na frente das casas, nas escolas e em momentos coletivos em que assistem televisão, são espaços de sociabilidade cada vez mais escassos, frente ao novo contexto após o início da construção da UHBM, tornando o futuro de crianças e jovens da agrovila como passível de preocupações sociais.

\section{REFERÊNCIAS}


| César Martins de Souza | Nelivaldo Cardoso Santana | Edilane Bezerra Amorim |

ALVITO, Marcos. A parte que te cabe neste latifúndio: o futebol brasileiro e a globalização. Análise Social - Revista do Instituto de Ciências Sociais da Universidade de Lisboa - Futebol Globalizado, Lisboa-Portugal, v. XLI, n. 179, p. 451-476, 2006.

CALDART, Roseli. Elementos para a construção de um projeto político e pedagógico da Educação do Campo. In: MOLINA, Mônica Castagna; JESUS, Sônia Meire de (Org.). Por uma educação do campo: contribuições para construção de um projeto de educação do campo. Brasília: Articulação Nacional Por uma Educação do Campo, 2004. p. 13-52.

CARDOSO, Fernando Henrique; MÜLLER Geraldo. Amazônia: expansão do capitalismo. São Paulo: Brasiliense, 1978.

CORRÊA, Sérgio Roberto. Currículo e Saberes: caminhos para uma educação do campo multicultural na Amazônia. In: HAGE, Salomão Mufarrej (Org.). Educação do campo na Amazônia: retratos de realidade das escolas multisseriadas no Pará. Belém: Gutemberg, 2005. p. 163-195.

GUEDES, Simone Lahud. O Brasil no campo de futebol: estudos antropológicos sobre os significados do futebol brasileiro. Niterói-RJ: EDUFF, 1998.

INGOLD, Tim. O dédalo e o labirinto: caminhar, imaginar e educar a atenção. Horizontes Antropológicos, Porto Alegre, n. 44, p. 21-36, jul./dez. 2015. Disponível em: < http://www.scielo.br/pdf/ha/v21n44/0104-7183-ha-21-44-0021.pdf $>$. Acesso em: 19 jan. 2016.

INSTITUTO SOCIOAMBIENTAL. Dossiê Belo Monte: não há condições para a Licença de Operação. ISA, 2015. Disponível em: < $\underline{\text { https://www.socioambiental.org/pt- }}$ br/dossie-belo-monte>. Acesso em: 12 fev. 2016.

MASCARENHAS, Suely [et al.]. Educação do campo na Amazônia brasileira - desafio acadêmico para o Sul do Amazonas. Revista Educamazônia - Educação, sociedade e meio ambiente, Humaitá-AM, v. 9, n. 2, p. 8-52, jul./dez. 2012. Disponível em: $<$ http://ieaa.ufam.edu.br/revistas/educamazonia/category/05-2012-volume-9/>. Acesso em: 19 jan. 2016.

MIRANDA NETO, José Queiroz de; HERRERA, José Antônio. Altamira-PA: novos papéis de centralidade e reestruturação urbana a partir da instalação da UHE Belo Monte. Confins - Revista Franco-Brasileira de Geografia, São Paulo, n. 28, p. 1-46, out. 2016. Disponível em: < $\underline{\text { https://journals.openedition.org/confins/11284> }}$. Acesso em: 02 maio 2019.

PEREIRA, Rosenildo da Costa; PEREIRA, Josiele Rodrigues. Educação do campo e educação rural no Brasil. Revista Travessias, Cascavel-PR, v. 10, n. 3, p. 121-125, 2016. Disponível em: <http://e-revista.unioeste.br/index.php/travessias/article/view/15051/ 10253 >. Acesso em: 03 maio 2019.

REGO, Renato Leão. Unidade de vizinhança: um estudo de caso das transformações de ideias urbanísticas. Urbe - Revista Brasileira de Gestão Urbana, Curitiba, v. 9, n. 3, p. 401-413, set./dez. 2017. Disponível em: $<$ https://periodicos.pucpr.br/index.php/Urbe/article/view/22102>. Acesso em: 13 nov. 2019. 
| César Martins de Souza | Nelivaldo Cardoso Santana | Edilane Bezerra Amorim |

SILVA, José Valtemir Ferreira da; SOUZA, César Martins de. A rodovia Transamazônica na Literatura: as faces da obra de Odete de Barros Mott. Revista de Literatura, História e Memória, Cascavél-PR, v. 14, n. 24, p. 274-291, dez. 2018. Disponível em: < $\underline{\text { http://e- }}$ revista.unioeste.br/index.php/rlhm/article/view/20634/13668>. Acesso em: 13 nov. 2019.

SOUZA, Maria Antônia de. Escola pública no/do campo, formação de professores e Projeto Político Pedagógico: experiências no contexto do Programa Observatório da Educação. Formação Docente - Revista Brasileira de Pesquisa sobre Formação Docente, Belo Horizonte, v. 9, n. 16, p. 27-48, 2017. Disponível em: $<$ https://revformacaodocente.com.br/index.php/rbpfp/article/view/160 >. Acesso em: 13 nov. 2019.

SOUZA, Maria Antônia de. Educação do campo: políticas, práticas pedagógicas e produção científica. Educação e sociedade, Campinas-SP, v. 29, n. 105, p. 1089-1111, set./dez. 2008. Disponível em: <http://www.cedes.unicamp.br>. Acesso em: 21 dez. 2015.

SOUZA, Orlando Nobre de; OLIVEIRA, Ney Cristina de. Cultura, educação e participação social: desafios educativos no contexto amazônico. In: ARAÚJO, Raimundo Marcos (Org.). Pesquisa em educação no Pará. Belém: EDUFPA, 2003. p. 203-224.

VENDRAMINI, Célia Regina. Qual o futuro das escolas no campo?. Educação em Revista, Belo Horizonte, v. 31, n. 03, p. 49-69, jul./set. 2015. Disponível em: < http://www.scielo.br/pdf/edur/v31n3/1982-6621-edur-31-03-00049.pdf $>$. Acesso em: 11 fev. 2017.

\section{Entrevistas:}

Entrevista com Rose em 13 de junho de 2004.

Entrevista com Mirla em 13 de junho de 2004.

Entrevista com Antônio em 08 de novembro de 2005.

Entrevista com João em 17 de novembro de 2005.

Entrevista com Mirla em 18 de novembro de 2015.

Entrevista com Festemino em 18 de novembro de 2015. 